\title{
Reactor physics analysis of the SPERT III E-core with TRIPOLI- $4{ }^{\circledR}$
}

\author{
Andrea Zoia ${ }^{\mathrm{a}, *}$, Emeric Brun ${ }^{\mathrm{a}}$ \\ ${ }^{a} C E A, D E N$, DM2S/SERMA/LTSD, Saclay \\ 91191 Gif-sur-Yvette, FRANCE.
}

\begin{abstract}
In this paper we detail a Monte Carlo model for the SPERT III E-core and we illustrate the simulation results obtained for the reactor physics parameters (including the effective multiplication factor, the reactivity worth of the core components and the kinetics parameters) by resorting to the production code TRIPOLI- ${ }^{\circledR}$. We have considered three reactor configurations, namely, initial core loading, zero cold power and hot zero power in stationary conditions, based on the large database of available experimental measurements. This analysis is aimed at establishing a firm background for the future investigation of the time-dependent behaviour of the E-core under reactivity excursions by resorting to reactor period calculations and dynamic Monte Carlo methods.
\end{abstract}

Keywords: SPERT III E-core, Kinetics parameters, Monte Carlo, TrIPOLI- $4^{\circledR}$

\section{Introduction}

The Special Power Excursion Reactor Test III (SPERT-III) is a small pressurized-water research reactor built and operated ${ }_{35}$ in the United States in the 1960s (Heffner and Wilson, 1961,

5 Houghtaling et al., 1965; McCardell et al., 1969). The main goal of SPERT-III was to analyze the kinetic behavior of nuclear reactors with the purpose of assessing the safety of the installation and the thermal-mechanical stress of the structural ${ }_{40}$ materials. Several core configurations have been successively

10 tested within the SPERT-III reactor: the E-core type consisted of a PWR-like core with $4.8 \%$-enriched $\mathrm{UO}_{2}$ fuel pellets arranged in a regular lattice of cylindrical pins, with moderator to non-moderator ratio equal to 0.971 (Heffner and Wilson, 1961, Houghtaling et al., 1965; McCardell et al., 1969). The E-core

15 has attracted a considerable amount of interest in view of the possibility of validating reactor physics and thermal-hydraulics codes in both steady-state and transient conditions. Concerning reactor physics, most of the previous analyses have been carried out by means of deterministic codes, which can be easily coupled with thermal-hydraulics codes, but suffer from various approximations (Kosaka et al., 1988; Ikeda and Takeda, 2001; Yamaji et al., 2014; Grandi and Moberg, 2012, Grandi, 2014; Aoki et al. 2009; Wang et al., 2013). In particular, the modelling of the complex and highly heterogeneous geometry of SPERT-III

25 has been often dealt with by resorting to spatial homogenization methods, which may induce some discrepancies in the estimation of the physical parameters (see for instance the discussion in (Cao et al., 2015)). More recently, Monte Carlo models for MCNP (X-5 Monte Carlo Team, 2003) and KENO (Bow- ${ }^{60}$ man, 2011) have been also proposed (Olson, 2013a b; Cao et al. 2015), and intensive efforts have been made in order to distil

\footnotetext{
*Corresponding author. Tel. +33 (0)1 69089544

Email address: andrea.zoia@cea.fr (Andrea Zoia)
}

the available technical information on the E-core specifications so as to propose an international benchmark for reactor physics analysis at IAEA (Olson, 2013c, IAEA, 2015).

In this paper, we provide the description of a detailed Monte Carlo model of the SPERT-III E-core and illustrate the results of the preliminary (static) reactor physics calculations of the reactivity worth and of the kinetics parameters carried out for this reactor configuration. Our analysis will be based on the production Monte Carlo code Tripoli- $4{ }^{\circledR}$, developed at the Commissariat à l'Energie Atomique (CEA) (Brun et al. 2015; TRIPOLI-4 Project Team, 2012).

Our aim is twofold: on one hand, we would like to extend the verification and validation database for TRIPOLI- $4{ }^{\circledR}$. In this respect, the large amount of technical papers describing the measurements performed during E-core startup, stationary operation and transient behaviour (Dugone, 1965; Heffner and Wilson, 1961, Houghtaling et al., 1965; McCardell et al. 1969; Potenza et al., 1966; Taxelius and Potenza 1967; Taxelius, 1967; Taxelius e al. 1967) makes SPERT-III an attractive configuration for the validation of the reactor physics capabilities of Monte Carlo codes, including the calculation of the effective multiplication factor, the void and temperature coefficients, and the kinetics parameters (effective delayed neutron fraction, effective mean generation time and reduced mean generation time).

On the other hand, this work sets the bases for further transient analyses of the E-core reactor kinetics under reactivity insertion by resorting to the asymptotic reactor period determination (Zoia et al., 2014a b) and to the so-called dynamic Monte Carlo methods (Sjenitzer and Hoogenboom, 2013), which are currently under development and will be released in a future version of TRIPOLI- $4{ }^{\circledR}$. Indeed, SPERT-III has been specially conceived to test the behavior of pressurized-water reactors at 65 low enrichment during power excursions initiated by reactivity insertion accidents, and a vast collection of experimental 
data concerning reactor period, power and temperature measurements is available in literature (McCardell et al., 1969).

This paper is structured as follows: in Sec. 2 we first provide 70 the description of the key elements of the E-core. The reference technical data were retrieved from the original SPERT reports (Dugone, 1965, Heffner and Wilson, 1961, Houghtaling et al. 1965: McCardell et al., 1969; Potenza et al., 1966; Taxelius and Potenza, 1967, Taxelius, 1967, Taxelius e al., 1967).

75 However, some uncertainties exist concerning some of the reactor components, so that in building our Monte Carlo model for TRIPOLI- ${ }^{\circledR}$ we will be compelled to make some assumptions. Then, in Sec. 3 we will illustrate the simulation results for the E-core reactor physics parameters in steady-state conditions as so obtained with TRIPOLI- $4{ }^{\circledR}$, and we will compare our numerical findings with the experimental measurements available in the literature. Finally, in Sec. 4 we will discuss the sensitivity of the simulation results to the modelling choices. Conclusions will be drawn in Sec. 5 .

\section{The Monte Carlo model of the SPERT-III E-core}

The reference configuration of the E-core contains 60 assemblies, including 48 fuel assemblies with $25(5 \times 5)$ pin-cells, 4 assemblies with $16(4 \times 4)$ pin-cells, and 8 control rods with fuel followers (yoked in pairs). A multi-layered stainless steel vessel surrounds the core. A transient cruciform poison rod is located at the center of the core: the rapid ejection of this rod is used to insert the necessary reactivity to initiate the desired power excursion (Heffner and Wilson, 1961; Houghtaling et al. 1965; McCardell et al., 1969). The general radial view of the

95 SPERT-III E-core is provided in Fig. 1

A detailed technical description of the facility can be found in the reports (Heffner and Wilson, 1961; Dugone, 1965; Houghtaling et al., 1965), and the results of the reactivity insertion experiments carried out in the SPERT-III, E-core are documented in (McCardell et al., 1969). Further elements concerning specific core components and the measurements of reactor physics parameters such as the temperature and void coefficients or the control rod worth can be found in (Potenza et al., 1966; Taxelius and Potenza, 1967, Taxelius, 1967). Specifications to generate international benchmark of the SPERT-III E core are being collected at IAEA (Olson, 2013a b c; IAEA, 2015). Nonetheless, some uncertainties still exist concerning a few construction parameters (Olson, 2013a b; IAEA, 2015, Cao et al., 2015). This in turn might considerably affect the results of the reactor physics calculations, such as the precise position of the control rods corresponding to criticality in steady-state conditions (Olson, 2013a b, Cao et al. 2015).

In the following, we summarize the features of the main components of the core (units will be provided as in the original

115 documents) and we comment on the modeling choices that have ${ }_{135}$ been made so as to build a Monte Carlo model of the SPERT-III E-core for TRIPOLI- $4{ }^{\circledR}$. In constructing the geometrical model, we closely follow the original specifications; when data are missing or unclear, we discuss our assumptions.
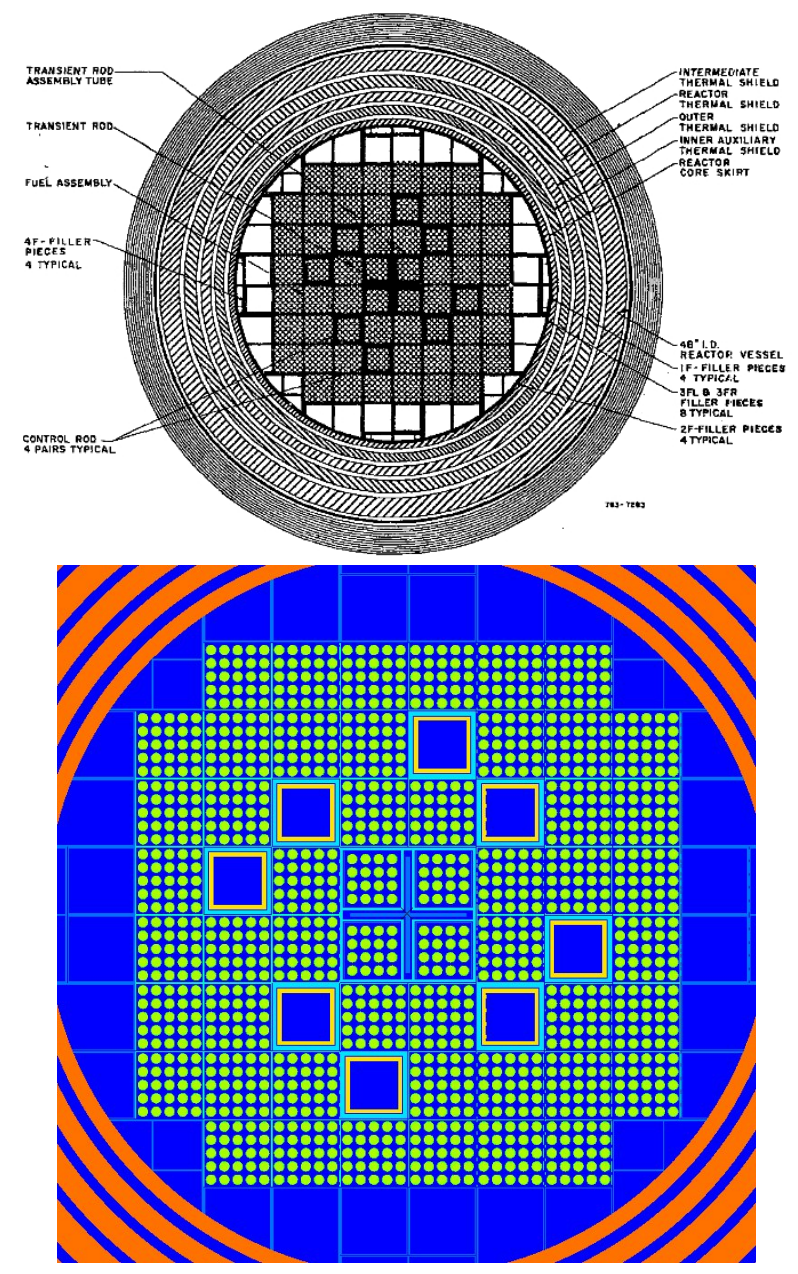

Figure 1: Top. Radial cut of the SPERT-III E-core with 60 assemblies, from Ref. (Dugone 1965). Bottom. Radial cut of the TRIPOLI-4 ${ }^{\circledR}$ model for the E-core at mid-plane.

\subsection{The fuel assemblies}

The geometrical description and the material compositions of the fuel pin-cells are provided in (Heffner and Wilson, 1961; Dugone, 1965; Houghtaling et al., 1965). The $\mathrm{UO}_{2}$ fuel (at $4.8 \%$ enrichment) comes in 0.42 in outer diameter pellets contained in 40.8 in long (excluding end plugs) by 0.426 in internal diameter SS348 stainless steel tubes, with a radial gas gap of 0.003 in between the pellets and the inner wall of the fuel cladding. The cladding has a wall thickness of $0.02 \mathrm{in.}$ The active fuel length in the core is 38.3 in (Dugone, 1965). There is an expansion gap of 2.5 in containing a compression spring (which we have homogenized) above the active height. The fuel rods are contained in SS348 assembly cans. Because of the presence of the central transient rod (see Fig. 1](top)) the core is composed of two types of fuel assemblies in order to preserve the symmetry of the lattice, namely $5 \times 5$ elements in the periphery and $4 \times 4$ elements close to the core center.

The standard $5 \times 5$ fuel element contains 25 fuel rods arranged in a regular 5x5 array with a pitch of 0.585 in (Dugone, 1965). The $5 \times 5$ assembly is illustrated in Fig. 2 (top). The SS348 


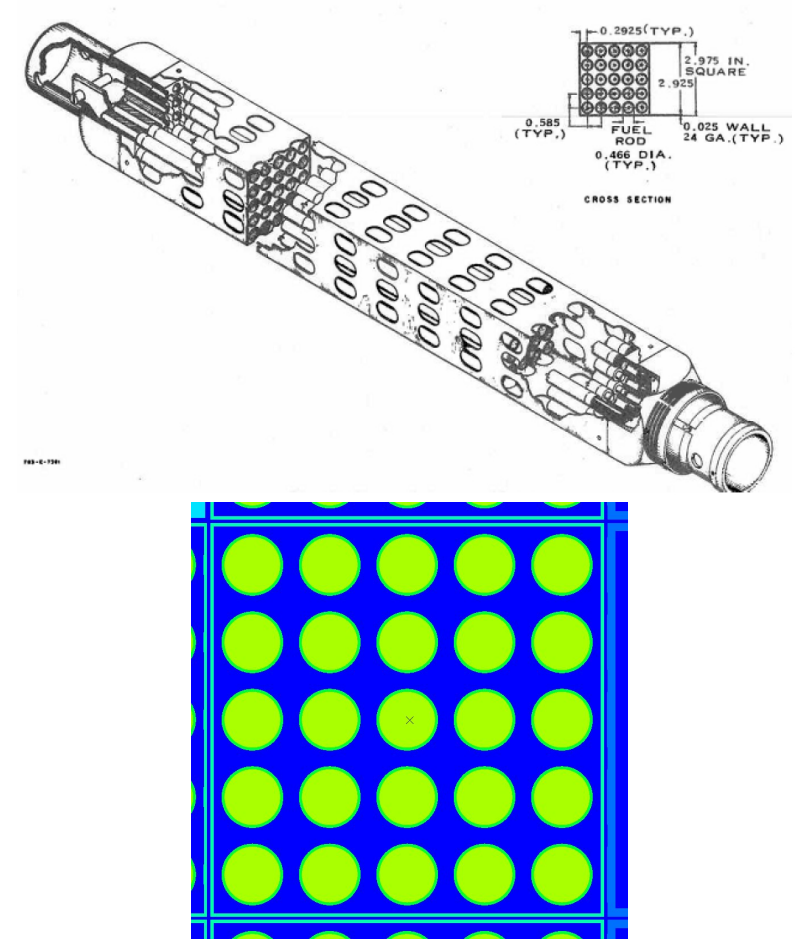

Figure 2: Top. The $5 \times 5$ fuel assembly, from Ref. (Dugone 1965). Bottom. Radial cut of the TrIPOLI- $4{ }^{\circledR}$ model for the $5 \times 5$ fuel assembly.

cladding of the $5 \times 5$ fuel assemblies is provided with holes al- ${ }^{170}$ lowing for horizontal water circulation for cooling purposes (see Fig. 2). The total surface of the holes is $120 \mathrm{in}^{2}$ (Dugone, 1965), but the precise details of the holes geometry are not known. In TRIPOLI- $4{ }^{\circledR}$, we have thus chosen to homogenize the water contained in the holes with the stainless steel cladding, ${ }^{17}$ similarly as previously done in other Monte Carlo models (Olson 2013a b, Cao et al., 2015). The upper and lower end plugs (which constrain the fuel elements into the upper and lower grids, respectively) are described in (Dugone, 1965). In TRIPOLI-4 ${ }^{\circledR}$ we have modeled the plugs as SS347 cylinders. The fuel elements are supported by intermediate grids, which we have neglected in our model. The radial description for the corresponding TRIPOLI- $4{ }^{\circledR}$ model is illustrated in Fig. 2 (bottom). The overall dimension of the $5 \times 5$ assemblies are 2.975 in wide by 2.975 in thick by 52.75 in long, including the end boxes to ${ }^{18}$ adapt the fuel elements to the upper and lower grids.

The $4 \times 4$ fuel assemblies are similar to the $5 \times 5$ assemblies, sharing the same fuel rods and the same pitch. The overall dimension of the $4 \times 4$ assemblies are 2.476 in wide by 2.476 in thick by 52.75 in long (Dugone, 1965).

\subsection{The control rods}

The E-core contains 8 control rods, yoked in pairs. Each rod is composed of an upper section made of a square box with ${ }^{195}$ $1.35 \%$ borated $18-8$ stainless steel (the poison, with a section of $2.476 \mathrm{in}$ square by a total length of $46 \mathrm{in}$, and a wall thickness of $0.186 \mathrm{in}$ ), and a lower section consisting in a fuel follower (a

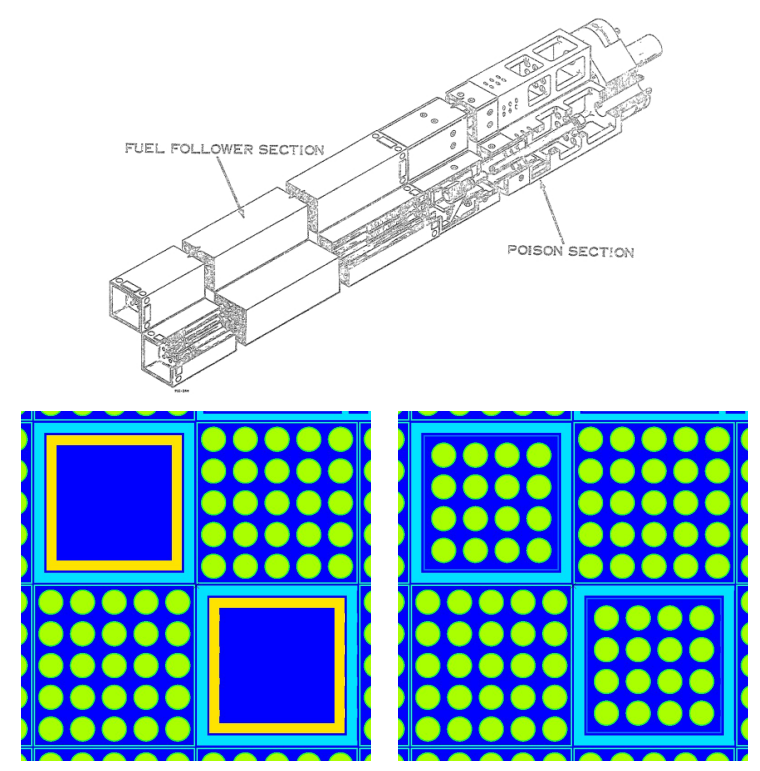

Figure 3: Top. A control rod pair, from Ref. (Dugone 1965). Bottom. Radial view of the poison sections (left) and fuel follower sections (right), respectively, of the control rod pairs in the TRIPOLI- $4{ }^{\circledR}$ model.

$4 \times 4$ fuel element, with a total length of 45-41/64 in) (Dugone, 1965). Both the poison portion and the fuel portion of the control rod can be fully inserted into the core. A control rod pair is illustrated in Fig. 3 (top).

The geometrical description of the upper and lower sections of the control rods is provided in (Dugone, 1965). The reference height for the position of the control rods within the core is taken to be the lower end of the upper (poison) section (Taxelius e al. 1967). The reference height is then expressed with respect to the lower end of the active fuel region (Dugone, 1965. Taxelius e al. 1967).

The control rods are protected by guide tubes made of Zircaloy-2, whose thickness may be deduced from (Heffner and Wilson, 1961; Houghtaling et al. 1965). The rubbing pads at the junction between the fuel section and the poison section have been neglected in our model. In order to prevent sharp discontinuities in the neutron flux, a flux suppressor made of two series of 6 small plates of $1.35 \%$ borated 18-8 stainless steel is located at the interface between the absorber section and the fuel section. Six suppressor plates have dimensions 2.184 by 1 by $0.03 \mathrm{in}$, and the six others have dimensions 2.34 by $2-23 / 32$ by $0.03 \mathrm{in}$. The complex shape and location of the flux suppressor can be retrieved from (Taxelius e al. 1967), a report describing problem in measuring the critical control rod position that occurred because of a misplaced poison plate belonging to a flux suppressor, and are illustrated in Fig. 4 (top and center).

In TRIPOLI-4 ${ }^{\circledR}$ we have accurately modeled the control rods, including the fine details of the flux suppressor plates and the grid between the upper and lower suppressor, without resorting to homogenization. The radial cut of the control rods used in the model is provided in Fig. 4(bottom). 


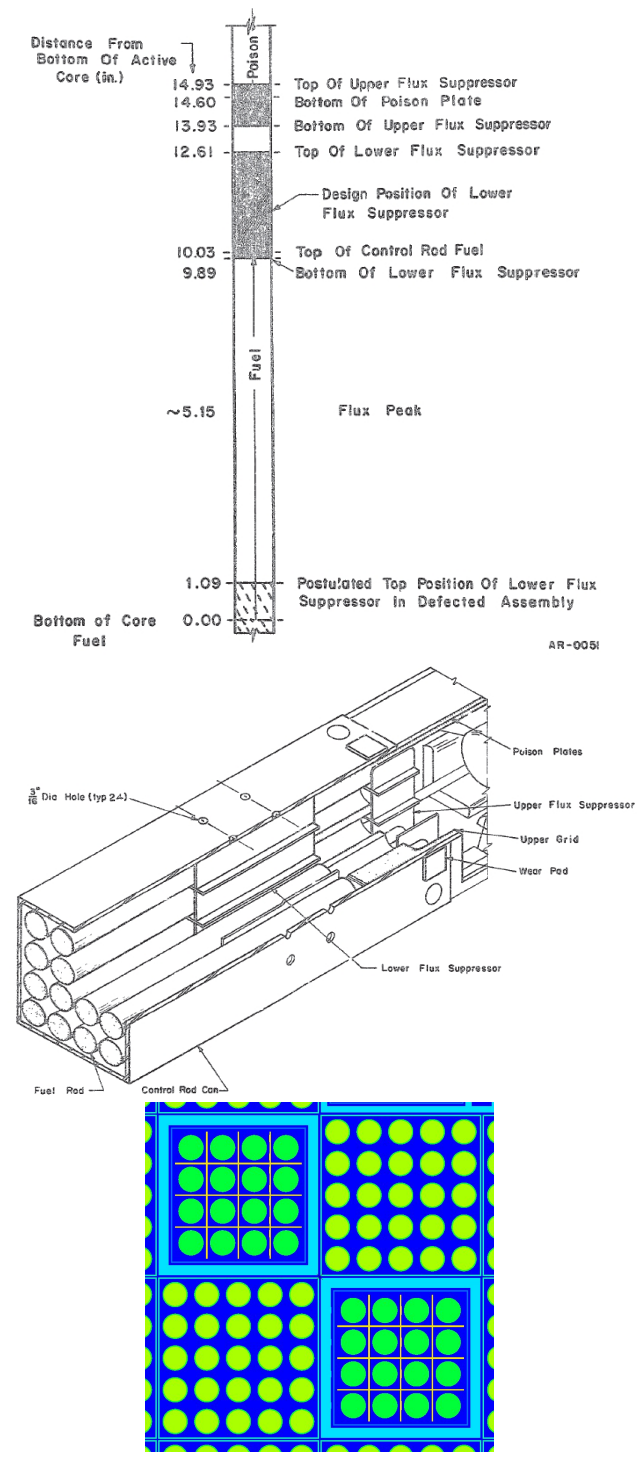

Figure 4: Top and center. Axial cut and close-up of the flux suppressor, from Ref. (Taxelius e al. 1967). Bottom. Radial cut showing the flux suppressor blades (at the junction between the absorber section and the fuel follower) in the control rod pair for the corresponding TRIPOLI- $4{ }^{\circledR}$ model.

\subsection{The cruciform transient rod}

The E-core contains a $5-1 / 8$ in wide by $3 / 16$ in thick cruciform transient control rod located at the center of the geometry (Dugone, 1965). The upper portion of the transient rod is made of 18-8 stainless steel and is entirely inserted into the core in nominal conditions. The lower portion of the transient rod is szo $_{20}$ made of $1.35 \%$ borated 18-8 stainless steel (with a length of $38 \mathrm{in}$ ) and is entirely located outside the core in nominal conditions (Dugone, 1965, McCardell et al., 1969). The geometry of the transient rod is illustrated in Fig. 5 (top). In order to respect the symmetry of the core, the 4 fuel elements located around ${ }_{235}$ the transient rod are of the $4 \times 4$ type (with the same kind of fuel rods and array pitch as for the $5 \times 5$ assemblies). The shape of the transient rod and of the $4 \times 4$ fuel elements can be retrieved from (Dugone, 1965). The transient rod and the 4 surrounding

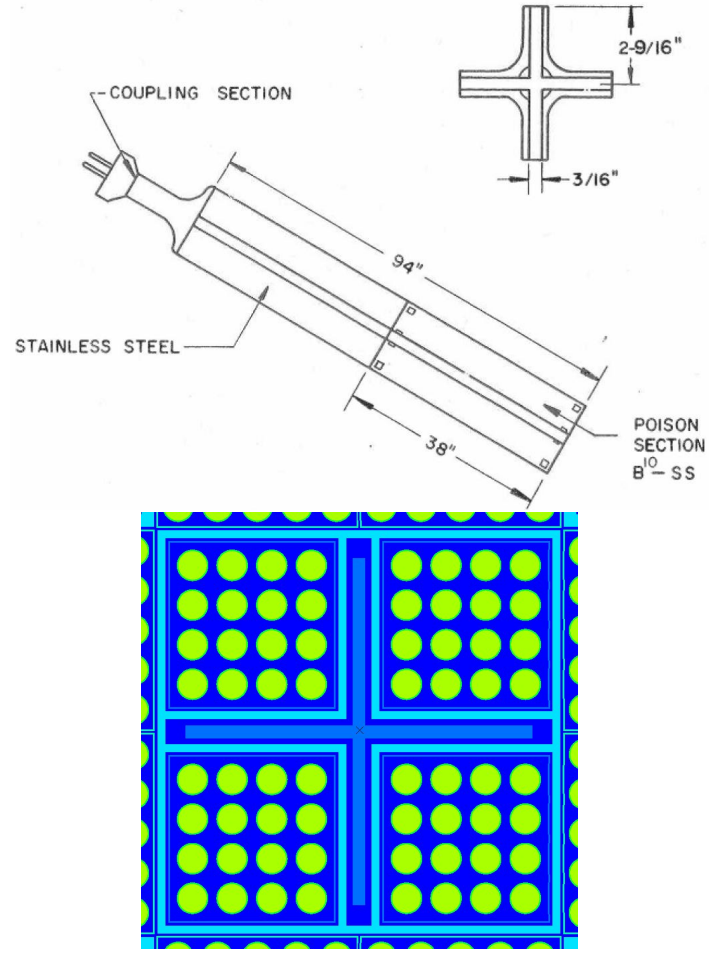

Figure 5: Top. The cruciform transient rod, from Ref. (Dugone 1965). Bottom. The Tripoli-4 ${ }^{\circledR}$ model for the transient rod and the $4 \times 4$ fuel elements at the center of the core.

fuel elements are protected by a guide tube made of Zircaloy2 (Dugone, 1965; Houghtaling et al., 1965). Fig. 5 (bottom) illustrates the radial cut of the Monte Carlo model including the transient rod and the $4 \times 4$ fuel assemblies. Unfortunately, the thickness of the guide tube and its precise position are not known. For our TrIPOLI- $4{ }^{\circledR}$ model, we have deduced a maximal thickness of $3 \mathrm{~mm}$, compatible with the geometrical constraints of the fuel element claddings and of the transient rod (Dugone, 1965; Houghtaling et al., 1965). The impact of this choice on the subsequent reactor physics calculations will be discussed in Sec. 4. The bushing pads positioning the blades into the guide tube are not expected to have a major impact, and have thus been neglected in our model.

\subsection{The vessel and the biological shield}

A multi-layered stainless steel vessel with an internal diameter of 48 in surrounds the core of SPERT-III (Dugone, 1965. Houghtaling et al., 1965). All inside surfaces in contact with water are clad with 304L stainless steel. Five concentric 304L stainless steel shells (a core skirt plus four shields) are alternated with water shells to prevent the radiation field from escaping from the core. A 6-inch-thick external biological shield made of ASTM B-29 lead surrounds the vessel, with a special insulating foam. The internal and external diameters of the steel shells and of the biological shield are provided in (Dugone, 1965; Houghtaling et al. 1965). The shells and the biological shield have been explicitly included in the Monte Carlo model 

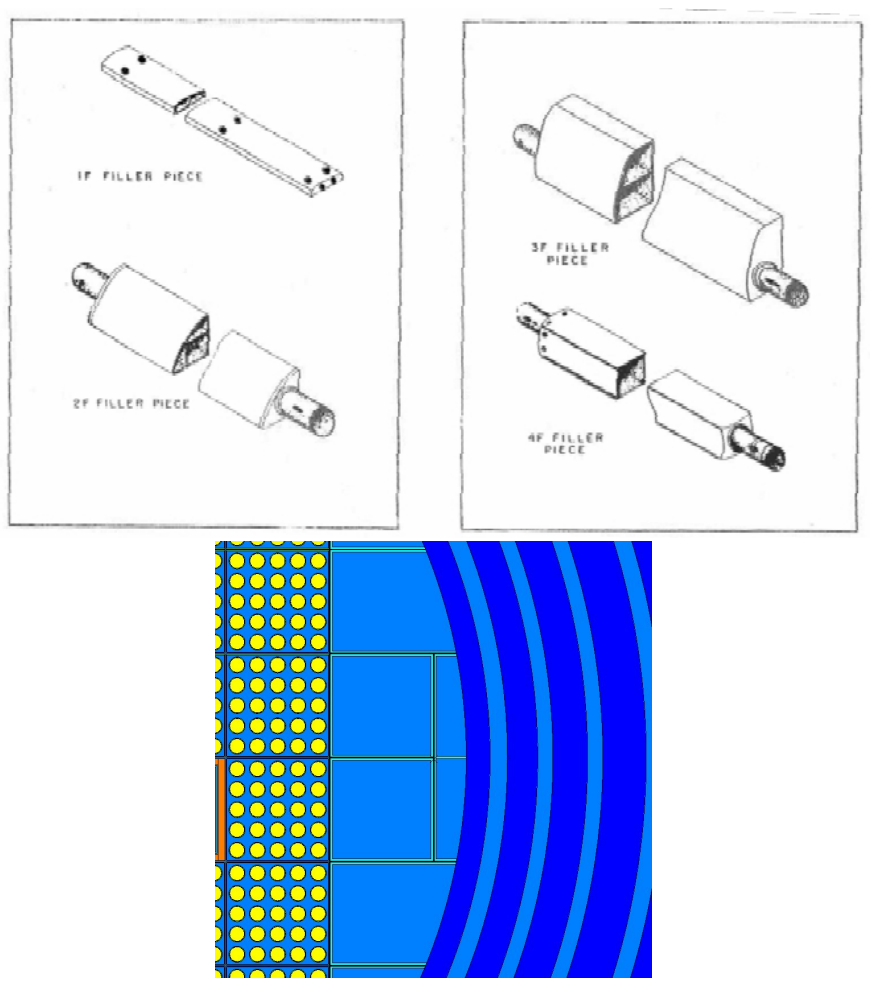

Figure 6: Top. The four types of core fillers, from Ref. (Dugone 1965). Bottom. Close-up of the filler pieces and the core skirts for the TRIPOLI- ${ }^{\circledR}$ model.

(see Fig. 6bottom), while the foam (which is expected to minimally affect the calculations) has been neglected.

\subsection{The filler pieces}

Since the reactor shape is cylindrical, the space between the fuel assemblies and the vessel is filled with special dummy spacer assemblies (similar to the $5 \times 5$ ) and special core fillers, consisting of 18-8 stainless steel plates, having a thickness of ${ }^{275}$ $1 / 8$ in (Dugone, 1965). The geometry of the filler pieces (which come in four kinds, to fit into the core) is given (Dugone, 1965) and is illustrated in Fig. 6 (top). The TrIPOLI- $4{ }^{\circledR}$ model, displayed in Fig. 6 (bottom), includes the external and internal plates of the fillers and neglects the internal tubes allowing for water feeding, whose precise description is not available in the original reports (since the filler pieces are peripheric with respect to the core, this assumption should have a minimal impact on the calculations).

\subsection{The upper and lower grids}

Upper and a lower 304L stainless steel grids support the fuel $2_{285}$ elements in the core. The lower grid has a thickness of 3 in and has a diameter of $31.97 \mathrm{in}$, with 64 holes corresponding to fuel element locations and core fillers, plus a cruciform hole for the transient rod. The upper grid has a thickness of 7 in and has a diameter of 42 in with 64 holes and square through holes for 290 the transient rod and the control rods. The description of the grids is provided in (Dugone, 1965; Heffner and Wilson, 1961),

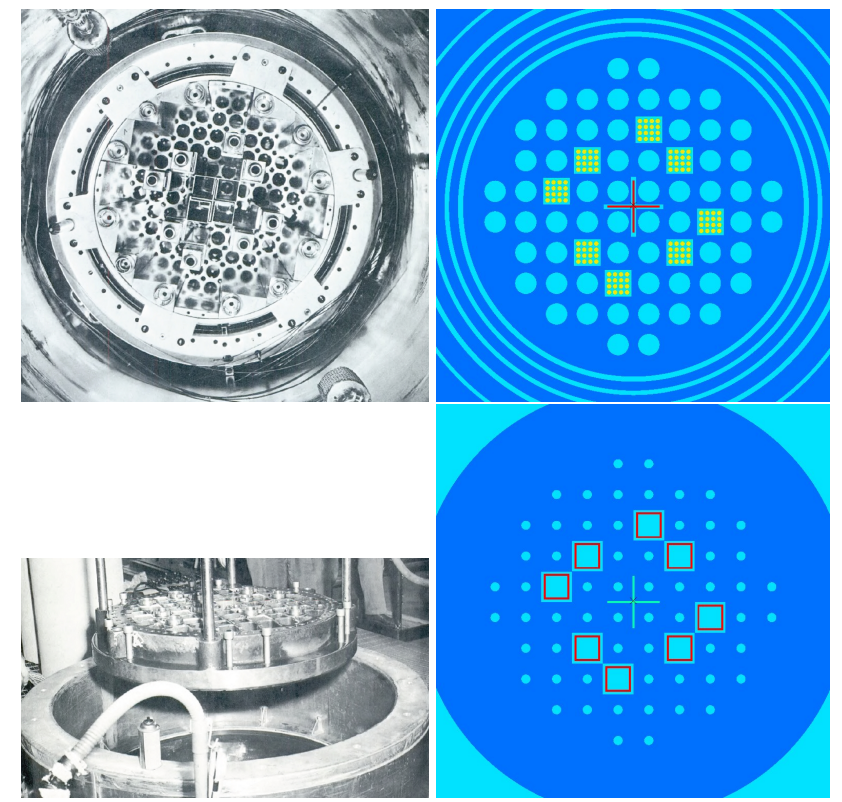

Figure 7: Top left and right. Lower reactor grids from Ref. (Dugone 1965), and the corresponding TRIPOLI- $4{ }^{\circledR}$ model. Bottom left and right. Upper reactor grids from Ref. (Dugone 1965), and the corresponding TRIPOLI-4 ${ }^{\circledR}$ model.

water circulation and for the passage of the control rods and the transient rod. Each fuel element is fixed to the grids by special elements, including end plugs and latches (Dugone, 1965, Heffner and Wilson, 1961). The upper and lower grids of the E-core are illustrated in Fig. 7. For the Tripoli- $4{ }^{\circledR}$ model we have included only the largest holes, and we have homogenized the end boxes of the fuel assemblies with the grids, as shown in Fig. 7

\subsection{Material compositions}

The material compositions for the E-core can be inferred from various references (Dugone, 1965, Heffner and Wilson. 1961; Houghtaling et al., 1965, McCardell et al., 1969). The choices that have been retained for the TRIPOLI- $4{ }^{\circledR}$ model are summarized in Appendix A

\section{Simulation results}

In the following, we illustrate the preliminary simulation results for reactivity, kinetics parameters and reactor physics coefficients in steady-state conditions obtained with TRIPOLI- $4{ }^{\circledR}$ for the SPERT-III E-core model described above. The water density was computed as a function of temperature and pressure, both for the moderator and for the homogenized composition (water and steel) in the $5 \times 5$ fuel assembly cans. Simulations were run by resorting to the JEFF3.1.1 nuclear data library with probability tables and $\mathrm{S}(\alpha, \beta)$ for hydrogen in water. Doppler broadening of the elastic scattering kernel was taken into account by using the DBRC model (Zoia et al., 2012) available in TrIPOLI- $4{ }^{\circledR}$ on every nuclide, up to a cutoff energy of 1 $\mathrm{keV}$. 


\subsection{Operational core loading at $70^{\circ} \mathrm{F}$}

The core loading procedure of SPERT-III was performed in 1966 (Potenza et al., 1966). The criticality was estimated to occur between 28 and 32 elements (including the fuel followers) at $70{ }^{\circ} \mathrm{F}$ and atmospheric pressure with the control rods completely withdrawn to their upper limit position (i.e., the fuel folowers completely inserted). The core was loaded four elements per step, and the first criticality was achieved with 32 elements (including the fuel followers) and the control rods banked into 26.5 in into the core (measured from the bottom of the active height of the fuel: this corresponds to $21.8 \mathrm{in}$ of fuel in the folowers drawn into the core) (Potenza et al., 1966). The uncertainty of the control rod position was estimated to be $\pm 0.01 \mathrm{in}$, which corresponds to about $4 \%$ of the total change in the control rod position, with an associated uncertainty in the reactivity variation per inch (at a given point) of about $5-6 \%$ (Taxelius, 1967). The loading pattern is illustrated in Fig. 8 (top). The configuration corresponding to the first criticality of the E-core has been modeled in TRIPOLI- $4{ }^{\circledR}$ : a radial cut is shown in Fig. 8 (bottom).

For this configuration, we have computed the effective multiyields $k_{\text {eff }}=1.00193 \pm 0.00011$, which is very close to criticality. The kinetics parameters for the core loading with 32 elements are not reported in the original documents. We have nonetheless computed the adjoint-weighted kinetics parameters with TRIPOLI- $4{ }^{\circledR}$ by resorting to the Iterated Fission Probability (IFP) method (Nauchi and Kameyama, 2010, Kiedrowski, 2011; Leppanen, 2014; Truchet et al., 2015), which yields $\beta_{\text {eff }}=778 \pm 4.6 \mathrm{pcm}$ for the effective delayed neutron fraction and $\Lambda_{\text {eff }}=22.2 \pm 0.02 \mu$ s for the effective mean genertime. For comparison, the typical values for a commercial 1000 MW PWR at 3.25\% enrichment and moderator to non-moderator ratio equal to $\sim 2$ are $\beta_{\text {eff }} \simeq 700 \mathrm{pcm}$ and $\Lambda_{\text {eff }} \simeq 25 \mu \mathrm{s}$ (Duderstadt and Hamilton, 1976). In order to evaluate the impact of the IFP method on the assessment of weighted kinetics parameters by resorting to the $\mathrm{IFP}_{0}$ approximated method, based on the expected number of fission neutrons in the next generation (Nauchi and Kameyama, 2005), which yields $\beta_{\text {eff }}^{0}=768 \pm 1.2 \mathrm{pcm}$ for the effective delayed 335 neutron fraction and $\Lambda_{\text {eff }}^{0}=25.8 \pm 0.007 \mu$ s for the effective mean generation time. The computed (un-weighted) delayed neutron fraction reads $\beta_{0}=724 \pm 0.8$ and the (un-weighted) mean generation time $\Lambda_{0}=45.8 \pm 0.02 \mu \mathrm{s}$.

\subsection{Static experiments of the operational core at $70^{\circ} \mathrm{F}$}

After achieving criticality, the core was fully loaded to the operational configuration with 60 elements (see Fig. 1), with all reactor components at $70{ }^{\circ} \mathrm{F}$ and atmospheric pressure (cold zero power condition). The critical rod height to achieve criticality is 14.6 in 1 from the bottom of the active fuel height (Potenza et al., 1966; Taxelius and Potenza, 1967,

\footnotetext{
${ }^{1}$ In (Potenza et al. 1966), the critical control rod height at cold wero power ${ }^{360}$ was reported to be $14.55 \mathrm{in}$, then 14.6. In all
}
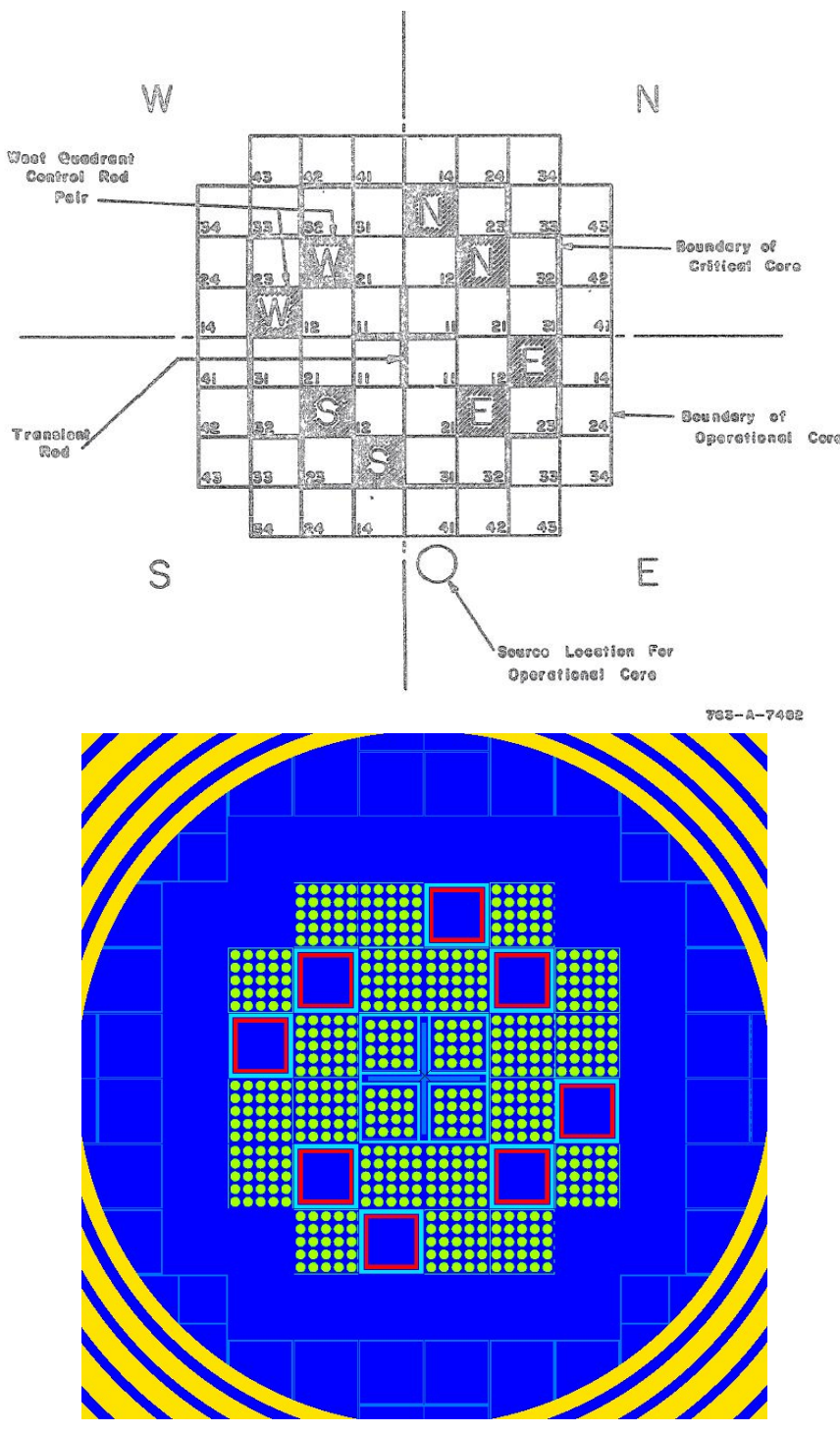

Figure 8: Top. The critical core loading of the E-core with 32 elements, from Ref. (Potenza et al. 1966). Bottom. Radial view of the corresponding TrIPOLI$4{ }^{\circledR}$ model.

Taxelius, 1967, McCardell et al., 1969). The simulated effective multiplication factor for this configuration reads $k_{\text {eff }}=$ $1.00139 \pm 0.00011$, which is very close to criticality.

The reduced mean generation time $\Lambda^{\dagger}=\Lambda_{\text {eff }} / \beta_{\text {eff }}$ has been sity technique), and reads $\Lambda^{\dagger}=2.15 \pm 0.008 \mathrm{~ms}$ (Taxelius and Potenza, 1967). Previous calculations based on perturbation theory had given $\Lambda^{\dagger}=1.91 \mathrm{~ms}$ (Taxelius and Potenza. 1967). Even though the uncertainty of the set of measurements is of the order of $1 \%$, for conservatism (because of the observed discrepancy with respect to the perturbation calculation) the uncertainty attributed to the reduced mean generation time has been evaluated at $12 \%$ (Taxelius, 1967). The kinetics parameters for this configuration had been separately computed by resorting to the deterministic codes DOPP-3C and COBRA, and read $\beta_{\text {eff }}=718 \mathrm{pcm}$ and $\Lambda_{\text {eff }}=15.55 \mu \mathrm{s}$ (McCardell et 

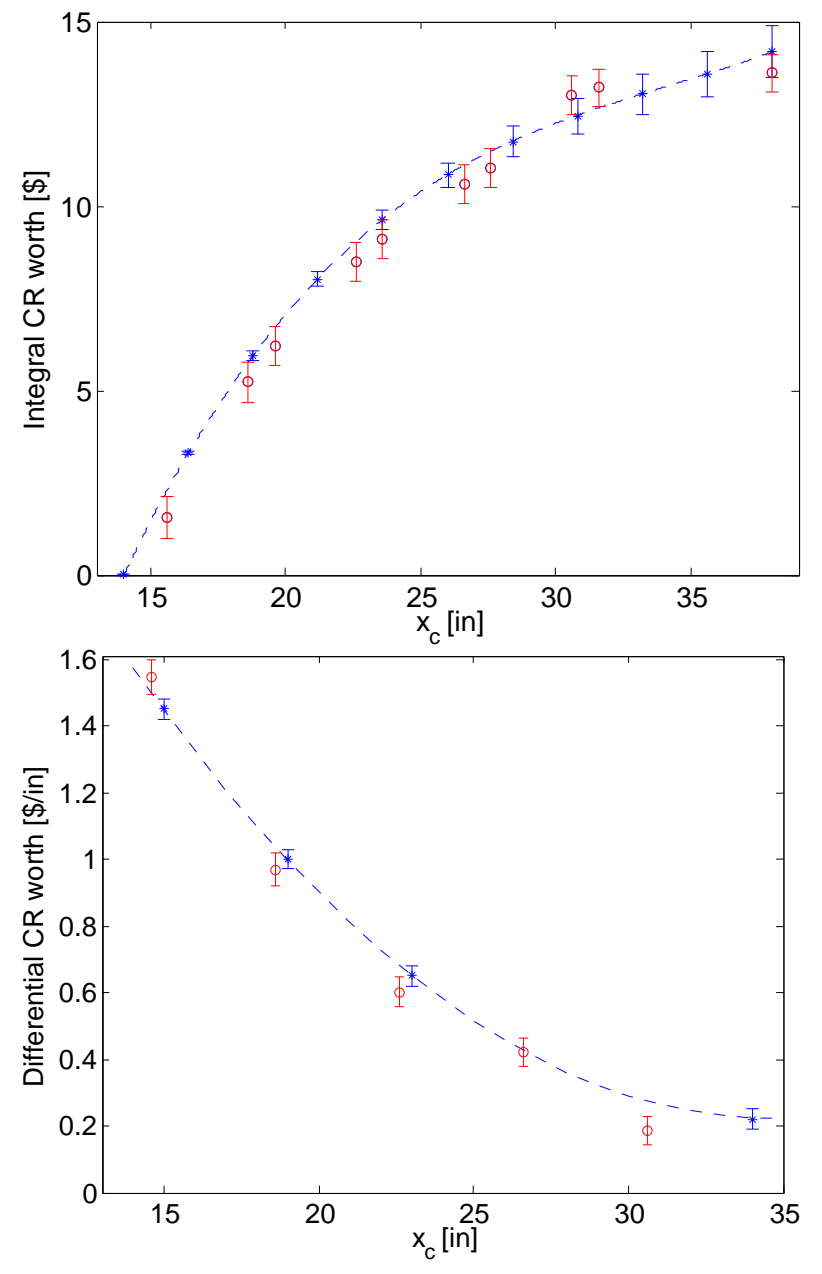

Figure 9: Integral (top) and differential (bottom) control rod worth for the operational core at cold zero power condition, expressed as a function of the control rod position $x_{c}$ with respect to the bottom of the active fuel height. Blue dashed curves represent the fits of the experimental results with the corresponding error bars for some measurements, taken from (Potenza et al. 1966, Taxelius and Potenza 1967, Taxelius 1967). Monte Carlo simulation results are displayed ${ }^{39}$ as red circles.

al. 1969). The estimated uncertainty for the delayed neutron fraction and of the mean generation time is of the order of 7$15 \%$ (assuming independence between $\beta_{\text {eff }}$ and $\Lambda^{\dagger}$ ) (McCardell et al., 1969, Olson, 2013a).

The TRIPOLI- $4{ }^{\circledR}$ model with IFP yields a reduced mean generation time $\Lambda^{\dagger}=2.27 \pm 0.01 \mathrm{~ms}$ (i.e., a ratio $C / M=1.056$ with respect to the measurement reported in (Taxelius and Potenza) ${ }^{400}$ 1967)), and the kinetics parameters $\beta_{\text {eff }}=761 \pm 4.6 \mathrm{pcm}$ (i.e., a ratio $C / C^{\prime}=1.06$ with respect to the value computed in $(\mathrm{Mc}-$ Cardell et al. 1969) ) and $\Lambda_{\text {eff }}=17.3 \pm 0.01 \mu$ s (i.e., a ratio $\left.C / C^{\prime}=1.11\right)$. These numerical findings are compatible with the measured and computed kinetics parameters reported above: the discrepancies with respect to the computed kinet- 405 ics parameters are most probably due to the approximations of the deterministic codes (simplified geometry and energy group meshes) and to the evolution of nuclear data libraries since the late 1960s. Observe that both the effective delayed neutron frac-

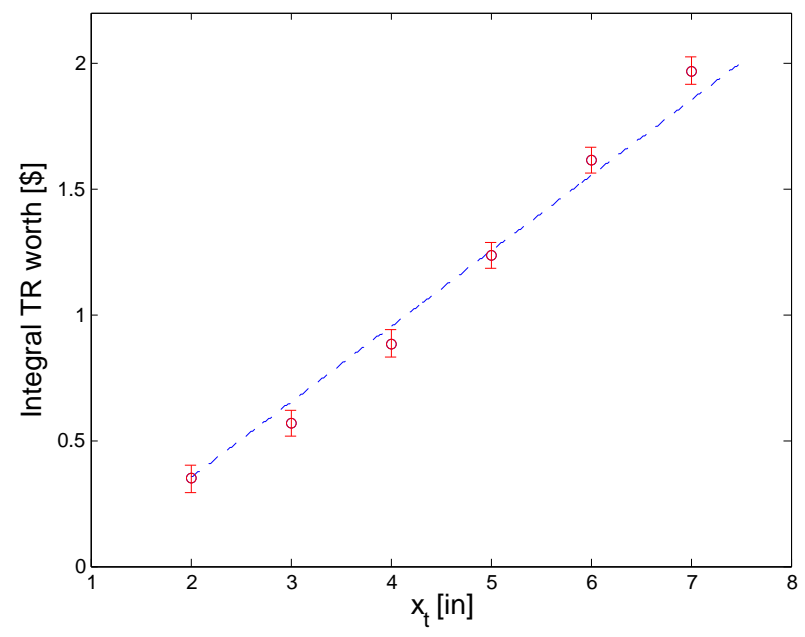

Figure 10: Integral transient rod worth for the operational core at cold zero power condition, expressed as a function of the transient rod position $x_{t}$ with respect to the bottom of the active fuel height. The blue dashed curve represent the fit of the experimental results taken from (McCardell et al. 1969), around the region of typical reactivity insertions for the E-core. Monte Carlo simulation results are displayed as red circles.

tion and the effective generation time for the operational core with 60 elements are lower than the respective values for the core loading with 32 elements. For comparison, we have also computed the IFP $_{0}$ kinetics parameters $\beta_{\text {eff }}^{0}=760 \pm 1.2 \mathrm{pcm}$ and $\Lambda_{\text {eff }}^{0}=18.8 \pm 0.005 \mu \mathrm{s}$, and the un-weighted kinetics parameters $\beta_{0}=729 \pm 0.7$ and $\Lambda_{0}=26.9 \pm 0.06 \mu \mathrm{s}$. The kinetics parameters 5 at $70{ }^{\circ} \mathrm{F}$ have been previously computed for the MCNP model of the SPERT-III E-core by resorting to the IFP method with the ENDF/B-VII nuclear data library, namely, $\beta_{e f f}=778 \pm 21 \mathrm{pcm}$ and $\Lambda_{\text {eff }}=17.72 \pm 0.06 \mu \mathrm{s}$, which gives $\Lambda^{\dagger}=2.28 \mathrm{~ms}$ (Olson, $2013 \mathrm{a}$ b).

\subsection{Reactivity worth of the operational core at $70^{\circ} \mathrm{F}$}

Several reactivity worth measurements have been carried out for the SPERT-III E-core during the fuel loading procedure and for the operational configuration with 60 elements (Potenza et al., 1966, Taxelius and Potenza, 1967; Taxelius, 1967; McCardell et al. 1969). For the following TrIPOLI $4{ }^{\circledR}$ calculations, we will express reactivity differences between two reactor configurations $a, b$ as $\Delta \rho=\left(1 / k_{\text {eff }}^{b}-1 / k_{\text {eff }}^{a}\right) / \beta_{\text {eff }}$ in dollar units $(\$)$, where for normalization we will assume the effective delayed neutron fraction $\beta_{\text {eff }}=761 \mathrm{pcm}$. As customary, we will use the symbol $\varnothing$ to denote $10^{-2} \$$.

\subsubsection{Control rods}

The control rod worth calibration has been reported in (Potenza et al. 1966, Taxelius and Potenza, 1967) and a statistical error analysis has been later performed in (Taxelius, 1967). The measured excess reactivity curve as a function of the control rod position $x_{c}$ (with respect to the bottom of the active core height) is shown in Fig. 9 (top), together with the reactivity excess computed with TRIPOLI- $4{ }^{\circledR}$. A good agreement is found between experimental measurements and Monte 
${ }_{410}$ Carlo calculations. The total reactivity excess for a clean cold core at $70{ }^{\circ} \mathrm{F}$ and atmospheric pressure when the control rods are completely extracted from the core (i.e., the fuel followers are completely inserted) has been initially reported to by 14.2 \$ (Potenza et al. 1966) and the measure was later refined to

$41513.1 \pm 0.7 \$$ (Taxelius, 1967). The maximum excess reactivity computed with TrIPOLI $-4{ }^{\circledR}$ is $13.6 \pm 0.051 \$$ (i.e., $C / M=1.04$ ).

The differential reactivity worth curve (expressed in $\$$ per inch of inserted control rod from the bottom of the active height of the core) has been also accurately determined in (Potenza et

420 al. 1966, Taxelius and Potenza, 1967, Taxelius, 1967) and is displayed in Fig. 9 (bottom) for the sake of completeness, together with the corresponding TRIPOLI- $4{ }^{\circledR}$ calculations. In particular, the differential control rod worth is reported to be 1.55 $\$ /$ in at the critical height (i.e., $x_{c}=14.6 \mathrm{in}$ ) in (Potenza et al. 1966): the value computed with TRIPOLI- $4{ }^{\circledR}$ by a variation of 1 in at the critical control rod position is $1.546 \pm 0.052 \$$ /in (i.e., $C / M=0.997)$.

\subsubsection{Transient rod}

The anti-reactivity due to the transient rod insertion has been experimentally measured (McCardell et al., 1969) in view of the calibration of reactivity insertion tests for the E-core. The corresponding curve is shown in Fig. 10 together with the TRIPOLI$4{ }^{\circledR}$ simulation results. In particular, the total anti-reactivity worth of the transient rod (corresponding to a full insertion) is reported to be about $4.6 \$$ (Potenza et al., 1966), with a differential worth of $0.3 \$$ /inch, averaged over the entire differential worth curve (McCardell et al., 1969). TRIPOLI-4 ${ }^{\circledR}$ calculations yield a total worth of $4.42 \pm 0.03 \$$ (i.e., $C / M=0.96$ ) with a differential worth of $0.32 \pm 0.04 \$$ /in (i.e., $C / M=1.07$ ), averaged $_{470}$ over all available points.

\subsubsection{Fuel assemblies}

The negative reactivity worth obtained by removing a central $4 \times 4$ fuel assembly (position S11) and a peripheral 5x5 fuel as- ${ }_{475}$ sembly (position E34) has been also determined: element S11 a worth of -1.9 \$ and element E34 has a worth of $-0.25 \$$ (uncertainties are not given) (Potenza et al. 1966). TRIPOLI- ${ }^{\circledR}$ calculations yield a worth of $-1.72 \pm 0.04 \$$ (i.e., $C / M=0.91$ ) for element $\mathrm{S} 11$ and a worth of $-0.29 \pm 0.04 \$$ (i.e., $C / M=1.16$ ) for element E34.

\section{3.4. Isothermal temperature coefficient of the operational core}

The changes in system reactivity due to variations in the water moderator have been experimentally determined in (Potenza et al., 1966, Taxelius, 1967) under steady state conditions. The isothermal temperature coefficient has been measured by uniformly varying the temperature of the reactor between approxi-48 mately $62^{\circ} \mathrm{F}$ and $581{ }^{\circ} \mathrm{F}$ by intervals of $50{ }^{\circ} \mathrm{F}$, the pressure being kept constant at 1740 psig. For each increase in temperature, the new critical rod position was determined and the temperature defect was computed by resorting to the differential control rod worth curve previously established. The temperature coef-490 ficient was finally obtained by dividing the temperature defect (expressed in dollars) by the temperature interval. The integral

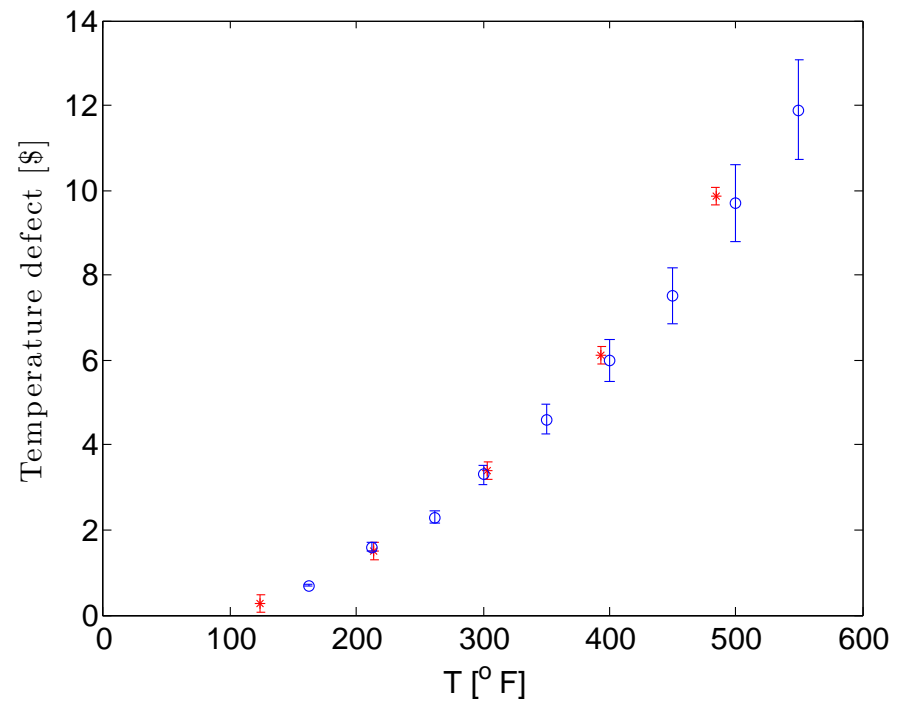

Figure 11: Isothermal excess reactivity for temperature increase from approximately $125^{\circ} \mathrm{F}$ to $550{ }^{\circ} \mathrm{F}$ at $1740 \mathrm{psig}$. Blue circles represent experimental measurements from Ref. (Potenza et al. 1966, Taxelius 1967). Monte Carlo simulation results are displayed as red stars.

temperature defect curve is displayed in Fig. 11 together with the corresponding results obtained by TRIPOLI- ${ }^{\circledR}$ by modifying the temperature of reactor components and re-computing the water density accordingly. The experimental error is evaluated to be of the order of $5 \%$ at $160{ }^{\circ} \mathrm{F}$ and increasing up to about $15 \%$ at $580{ }^{\circ} \mathrm{F}$. The isothermal temperature coefficient is reported to be $-0.4 \phi /{ }^{\circ} \mathrm{F}$ at a temperature of $70{ }^{\circ} \mathrm{F},-1.36 \pm 0.04$ $\phi /{ }^{\circ} \mathrm{F}$ at a temperature of $190{ }^{\circ} \mathrm{F}$ and $-4.8 \pm 0.8 \phi /{ }^{\circ} \mathrm{F}$ at a temperature of $565^{\circ} \mathrm{F}$ (Potenza et al., 1966) (observe however that in (Taxelius, 1967) the isothermal temperature coefficient was reported to be $-6.7 \phi /{ }^{\circ} \mathrm{F}$ at a temperature of $556{ }^{\circ} \mathrm{F}$, which possibly stems from an increased uncertainty at high temperature). With Tripoli- $4{ }^{\circledR}$ we have obtained $-0.45 \pm 0.01 \phi /{ }^{\circ} \mathrm{F}$ (i.e., $C / M=1.12$ ) at a temperature of $70{ }^{\circ} \mathrm{F},-1.38 \pm 0.009 \phi /{ }^{\circ} \mathrm{F}$ at a temperature of $170{ }^{\circ} \mathrm{F}$, and $-6.8 \pm 0.01 \phi /{ }^{\circ} \mathrm{F}$ at a temperature of $530^{\circ} \mathrm{F}$.

\subsection{Other reactivity coefficients of the operational core}

Several other reactivity coefficients have been either experimentally determined or numerically computed for the operational core at cold zero power conditions (Potenza et al., 1966 , Taxelius and Potenza, 1967; Taxelius, 1967; McCardell et al. 1969). The static pressure reactivity coefficient was measured by first bringing the reactor to criticality at steady state with uniform temperature and a given pressure. Then, the system pressure is increased (at constant temperature) and reactivity is reestablished by adjusting the control rod position: by resorting to the differential control rod worth curve, the average change in reactivity per unit pressure is therefore measured. The pressure coefficient in the temperature range from about $150{ }^{\circ} \mathrm{F}$ to 300 ${ }_{\square}^{\circ} \mathrm{F}$ is roughly constant and reads $0.016 \pm 0.001 \phi /{ }^{\circ} \mathrm{F}$ (Potenza et 
al. 1966) ${ }^{2}$ The pressure coefficient computed with TRIPOLI- ${ }^{\circledR}$ yields $0.014 \pm 0.001 \varnothing /{ }^{\circ} \mathrm{F}$ at $214^{\circ} \mathrm{F}$ (corresponding to a variation of 1000 psig at constant temperature), which corresponds to $C / M=0.88$.

The void coefficient has been experimentally measured by ${ }_{545}$ replacing the moderator with aluminum wires and determining the corresponding change in system reactivity. When aluminum ires are applied uniformly throughout the core, the void coefficient reads $-0.5 \pm 0.025 \$ / \%$ void at $70{ }^{\circ} \mathrm{F}$ (Taxelius and Potenza, 1967). The value computed by TRIPOLI- $4{ }^{\circledR}$ by assum-550 ing a variation of $1 \%$ in the water moderator density in the whole core region is $-0.44 \pm 0.02 \$ / \%$ void (i.e., $C / M=0.88$ ).

505 Finally, the Doppler coefficient was computed by resorting to the deterministic codes DOPP-3C and CORA, and was determined to be $-0.72 \phi /{ }^{\circ} \mathrm{F}$ at $70{ }^{\circ} \mathrm{F}$ (McCardell et al., 1969). 555 In (Wang et al., 2013), the Doppler coefficient was also computed by resorting to the coupled deterministic codes TRITON/PARCS and ENDF/B-VII nuclear data library, to give $-0.248 \phi /{ }^{\circ} \mathrm{F}$. The Tripoli- $4{ }^{\circledR}$ calculation for the Doppler coefficient yields $-0.28 \pm 0.02 \phi /{ }^{\circ} \mathrm{F}$, corresponding to a variation of the fuel temperature from $70{ }^{\circ} \mathrm{F}$ to $105.5^{\circ} \mathrm{F}$.

\subsection{Analysis of the operational core at $550^{\circ} \mathrm{F}$}

The behavior of the operational core at $550{ }^{\circ} \mathrm{F}$ and 1740 psig (hot zero power condition) and the corresponding reactivity worth of its components have been measured and are ${ }^{565}$ reported in (Potenza et al., 1966). The critical control rod height is 28.25 in from the bottom of the active height of the 520 core (Potenza et al., 1966). The effective multiplication coefficient computed with TRIPOLI- $4{ }^{\circledR}$ by resorting to the JEFF3.1.1 nuclear data library at the critical control rod height is $k_{e f f}={ }^{570}$ $1.00151 \pm 0.00011$, which is very close to criticality.

The kinetics parameters for the operational core at $500{ }^{\circ} \mathrm{F}$ had been computed by the deterministic codes DOPP-3C and CORA, and read $\Lambda^{\dagger}=2.25 \mathrm{~ms}, \beta_{\text {eff }}=725 \mathrm{pcm}$ and $\Lambda_{\text {eff }}=$ $16.31 \mu \mathrm{s}$ (McCardell et al., 1969), which shows that these values are rather insensitive to temperature variations. At 550 ${ }^{\circ} \mathrm{F}$, the kinetics parameters computed by TRIPOLI- $4{ }^{\circledR}$ with the IFP method read $\Lambda^{\dagger}=2.27 \pm 0.01 \mathrm{~ms}$ (i.e., $C / C^{\prime}=1.009$ ), $\beta_{\text {eff }}=765 \pm 4.4 \mathrm{pcm}$ (i.e., $C / C^{\prime}=1.06$ ), and $\Lambda_{\text {eff }}=17.4 \pm 0.015$ $\mu$ s (i.e., $C / C^{\prime}=1.07$ ) ${ }^{3}$. For comparison, we have also computed the $\mathrm{IFP}_{0}$ kinetics parameters $\beta_{\text {eff }}^{0}=758 \pm 1.4 \mathrm{pcm}$ and $\Lambda_{\text {eff }}^{0}=19.2 \pm 0.004 \mu \mathrm{s}$, and the un-weighted kinetics parameters $\beta_{0}=738 \pm 0.6$ and $\Lambda_{0}=25.2 \pm 0.07 \mu \mathrm{s}$. The kinetics parameters at $500{ }^{\circ} \mathrm{F}$ have been previously computed for the MCNP model of ${ }_{585}$ the SPERT-III E-core by resorting to the IFP method with the ENDF/B-VII nuclear data library, namely, $\beta_{\text {eff }}=745 \pm 21 \mathrm{pcm}$ and $\Lambda_{e f f}=18.0 \pm 0.06 \mu \mathrm{s}$, which gives $\Lambda^{\dagger}=2.42 \mathrm{~ms}$ (Olson, $2013 \mathrm{a}$ b).

\footnotetext{
${ }^{2}$ The uncertainty has been estimated based on the data displayed in Fig. 8 of (Potenza et al. 1966), in the temperature range from $150{ }^{\circ} \mathrm{F}$ to $300{ }^{\circ} \mathrm{F}$.

${ }^{5}$ For the $C / C^{\prime}$ ratios, we have assumed that the values computed in $\mathrm{Mc}$ Cardell et al. 1969) at $500^{\circ} \mathrm{F}$ be unchanged at $550{ }^{\circ} \mathrm{F}$.
}

\subsubsection{Reactivity worth of the operational core at $550^{\circ} \mathrm{F}$}

For the operational core at $550^{\circ} \mathrm{F}$, we will assume that the effective delayed neutron fraction to normalize reactivities computed by TRIPOLI- $4{ }^{\circledR}$ is $\beta_{\text {eff }}=765 \mathrm{pcm}$, as obtained by using the IFP method.

The available reactivity excess at $550{ }^{\circ} \mathrm{F}$ is reported to be 2.5 $\$$ (no uncertainty provided) (Potenza et al., 1966), and the value computed by TRIPOLI- $4{ }^{\circledR}$ reads $3.1 \pm 0.04 \$$, corresponding to $C / M=1.24$.

The differential control rod worth close to the critical position has been experimentally measured and yields $0.41 \$$ in (Potenza et al., 1966), and the TrIPOLI- ${ }^{\circledR}$ model gives $0.48 \pm 0.015 \$$ /in (i.e., $C / M=1.17$ ).

Finally, the total reactivity worth of the transient rod is reported to be rather insensitive to temperature variations (4.7 \$ at $500{ }^{\circ} \mathrm{F}$ (McCardell et al., 1969) $)$, and the TrIPOLI- $4{ }^{\circledR}$ calculation gives $5.11 \pm 0.02 \$$ (i.e., $C / M=1.09$ ).

\section{Sensitivity to geometrical and material data}

The Monte Carlo simulation results reported in this work depend on the assumptions taken with respect to the aforementioned uncertainties in the reactor geometry, on the material compositions of the core components, as well as on the choice of the nuclear data library. It would be therefore important to fully assess the sensitivities of reactor physics parameters with respect to the key hypotheses introduced in the Monte Carlo model. While a systematic analysis is beyond the scope of the present paper, in the following we will discuss some relevant points.

In all of our TRIPOLI- $4{ }^{\circledR}$ calculations, we have resorted to the JEFF3.1.1 nuclear data library. For comparison, we have recomputed the reactivity and kinetics parameters of the operational core at cold zero power conditions by resorting to the ENDF/B-VII.0 nuclear data library. In both cases, we have used the probability tables and the DBRC model for the Doppler broadening of the elastic scattering kernel. For this configuration, TRIPOLI- $4{ }^{\circledR}$ yields an effective multiplication factor $k_{\text {eff }}=1.00163 \pm 0.00011$, which means a difference of +24 pcm with respect to the calculation performed with JEFF3.1.1. As for the kinetics parameters, with the IFP method we obtain the reduced mean generation time $\Lambda^{\dagger}=2.34 \pm 0.02 \mathrm{~ms}$ (corresponding to a variation of $+3 \%$ with respect to JEFF3.1.1), the effective delayed neutron fraction $\beta_{\text {eff }}=739 \pm 6.2 \mathrm{pcm}$ (i.e., $-2.9 \%)$ and the effective generation time $\Lambda_{\text {eff }}=17.3 \pm 0.02$ $\mu$ s (unchanged wth respect to JEFF3.1.1). We have also computed the $\mathrm{IFP}_{0}$ kinetics parameters $\beta_{\text {eff }}^{0}=734 \pm 1.6 \mathrm{pcm}$ and $\Lambda_{e f f}^{0}=18.8 \pm 0.007 \mu \mathrm{s}$, and the un-weighted kinetics parameters $\beta_{0}=708 \pm 0.7$ and $\Lambda_{0}=26.8 \pm 0.07 \mu \mathrm{s}$. The (weighted or un-weighted) generation time is unaffected by the change in the nuclear data library, whereas the (weighted or un-weighted) delayed neutron fraction shows a larger discrepancy: since the un-weighted $\beta^{0}$ has also a variation of $-3 \%$, we can possibly attribute this discrepancy to differences affecting the mean number of delayed neutrons per fission in the two nuclear data libraries. 
We could not retrieve the thickness of the Zircaloy-2 guide tubes of the transient rod from the SPERT reports. As detailed above, we have made a hypothesis concerning the tube thick-650 ness based on the geometrical constraints imposed by the $4 \times 4$ fuel elements and by the cruciform transient rod. Also, we have the guide tube emerging from the lower reactor grid (see Fig. 7 , top left). Nonetheless, the thickness may still vary by several millimeters. We have thus assessed the impact of this parameter on the system reactivity: at $70{ }^{\circ} \mathrm{F}$, TrIPOLI- $4{ }^{\circledR}$ yields an 605 effective multiplication factor $k_{e f f}=1.00230 \pm 0.00011$ when reducing the Zircaloy-2 guide tube by $1 \mathrm{~mm}$ in the operational core configuration, which corresponds to a variation of about $+91 \mathrm{pcm}$ with respect to our reference model. As for the kinetics parameters (computed by using the IFP method), for the configuration with reduced guide tube thickness we get the reduced mean generation time $\Lambda^{\dagger}=2.24 \pm 0.01 \mathrm{~ms}(-3 \%$ with respect to the reference model), the effective delayed neutron fraction $\beta_{\text {eff }}=774 \pm 5.1 \mathrm{pcm}(+2 \%)$ and the effective generation time $\Lambda_{\text {eff }}=17.4 \pm 0.01 \mu \mathrm{s}(+0.6 \%)$.

Finally, we have assessed the impact of the stainless steel density in the material composition. We have re-run the operational core configuration at $70{ }^{\circ} \mathrm{F}$ by modifying the density of 304 and 304L stainless steel (used for most structural materials in the reactor) from the reference value $7.94 \mathrm{~g} / \mathrm{cm}^{3}$ to 8.00 $\mathrm{g} / \mathrm{cm}^{3}$. The effective multiplication factor for the perturbed configurations reads $k_{\text {eff }}=1.00117 \pm 0.00011$, which corresponds to a variation of about $-22 \mathrm{pcm}$ with respect to our reference model. As for the kinetics parameters, with the IFP method we get the reduced mean generation time $\Lambda^{\dagger}=2.25 \pm 0.01 \mathrm{~ms}$, the effective delayed neutron fraction $\beta_{\text {eff }}=768 \pm 5.3 \mathrm{pcm}$ and the effective generation time $\Lambda_{\text {eff }}=17.3 \pm 0.01 \mu \mathrm{s}$.

\section{Conclusions}

The preliminary analysis of the reactor physics parameters of the SPERT III E-core based on the TRIPOLI- $4{ }^{\circledR}$ Monte Carlo model is on the whole satisfactory. The values obtained with TRIPOLI- $4{ }^{\circledR}$ for the steady-state reactor configurations at both cold zero power and hot zero power conditions are in good agreement with the experimental measurements and with the data computed in the original reports. These results suggest that the essential features of the E-core have been captured in the proposed Monte Carlo model.

Future work on the SPERT III E-core will be aimed at $i$ ) extending the sensitivity analysis of the TRIPOLI- $4{ }^{\circledR}$ model, so as to confirm or question the assumptions made on the geometrical details and on the compositions; and ii) at computing by Monte Carlo methods the asymptotic reactor period and the time-dependent behaviour of the neutron population under reactivity excursions, based on the experimental measurements reported in (McCardell et al. 1969).

\section{Acknowledgments}

The authors express their gratitude to Drs. A. Olson (ANL) and D. Ridikas (IAEA) for many fruitful discussions and for kindly sharing their knowledge on the E-core configuration, and to Drs. C. Poinot-Salanon and F. Damian (CEA) for carefully reading the manuscript. TRIPOLI ${ }^{\circledR}$ and TRIPOLI- $4{ }^{\circledR}$ are registered trademarks of CEA. The authors wish to thank AREVA and Électricité de France (EDF) for partial financial support.

\section{Appendix A. Material compositions}

In the following tables we provide the specifications for material composions and densities for various reactor components at $70{ }^{\circ} \mathrm{F}$ and atmospheric pressure. We have followed ASME specifications ${ }^{4}$ by taking averages over proposed ranges of densities where needed. For 18-8 stainless steel, we have taken the specifications of $304 \mathrm{SS}$ steel. For the $1.35 \%$ borated steel, we have taken the specifications of 304SSB5, whose typical enrichment range corresponds to the material used for the E-core (see, for instance, (He et al., 2011)).

\begin{tabular}{lc}
\hline & $\mathrm{UO} 2\left(10.5 \mathrm{~g} / \mathrm{cm}^{3}\right)$ \\
\hline $\mathrm{U} 234$ & 0.0003522 \\
$\mathrm{U} 235$ & 0.0423083 \\
$\mathrm{U} 236$ & 0.0001674 \\
$\mathrm{U} 238$ & 0.8385893 \\
O16 & 0.1185826 \\
\hline
\end{tabular}

Table A.1: Composition of fuel pins at nominal density.

\begin{tabular}{lc}
\hline & MODERATOR $\left(0.99803 \mathrm{~g} / \mathrm{cm}^{3}\right)$ \\
\hline $\mathrm{H} 1$ & 0.11111 \\
$\mathrm{O} 16$ & 0.88889 \\
\hline
\end{tabular}

Table A.2: Composition of water moderator at $70^{\circ} \mathrm{F}$ and atmospheric pressure.

\begin{tabular}{lc}
\hline & 304SS $\left(7.94 \mathrm{~g} / \mathrm{cm}^{3}\right)$ \\
\hline $\mathrm{C}$ & 0.0004 \\
CR & 0.19 \\
MN55 & 0.01 \\
N & 0.0005 \\
NI & 0.0925 \\
P & 0.000225 \\
SI & 0.00375 \\
S & 0.00015 \\
FE & 0.702475 \\
\hline
\end{tabular}

Table A.3: Composition of 304SS and 18-8 stainless steel.

\section{References}

Aoki, S., Suemura, T., Ogawa, J., Takeda, T., 2009. J. Nucl. Sci. Techn. 46, 239-251.

\footnotetext{
${ }^{4}$ https://www.asme.org/
} 


\begin{tabular}{lc}
\hline & 304LSS $\left(7.94 \mathrm{~g} / \mathrm{cm}^{3}\right)$ \\
\hline $\mathrm{C}$ & 0.00015 \\
$\mathrm{CR}$ & 0.19 \\
MN55 & 0.01 \\
$\mathrm{~N}$ & 0.0005 \\
$\mathrm{NI}$ & 0.1 \\
$\mathrm{P}$ & 0.000225 \\
SI & 0.00375 \\
S & 0.00015 \\
FE & 0.695225 \\
\hline
\end{tabular}

Table A.4: Composition of 304LSS stainless steel

\begin{tabular}{lc}
\hline & 348SS $\left(8.00 \mathrm{~g} / \mathrm{cm}^{3}\right)$ \\
\hline C & 0.0004 \\
CR & 0.18 \\
MN55 & 0.01 \\
NI & 0.11 \\
P & 0.000225 \\
SI & 0.00375 \\
S & 0.00015 \\
NB & 0.004 \\
TA & 0.0005 \\
CO & 0.001 \\
FE & 0.689975 \\
\hline
\end{tabular}

Table A.5: Composition of 348SS stainless steel.

\begin{tabular}{lc}
\hline & 304SSB5 $\left(7.79 \mathrm{~g} / \mathrm{cm}^{3}\right)$ \\
\hline B10 & 0.0135 \\
C & 0.00040 \\
CO & 0.001 \\
CR & 0.19 \\
MN55 & 0.01 \\
N & 0.0005 \\
NI & 0.135 \\
P & 0.000225 \\
SI & 0.00375 \\
S & 0.00015 \\
FE & 0.645475 \\
\hline
\end{tabular}

Table A.6: Composition of 304SSB5 stainless steel.

\begin{tabular}{lc}
\hline & LEAD $\left(11.37 \mathrm{~g} / \mathrm{cm}^{3}\right)$ \\
\hline PB207 & 0.9994 \\
SB121 & 0.00001 \\
AS75 & 0.00001 \\
SN119 & 0.00001 \\
CU65 & 0.000015 \\
AG107 & 0.000050 \\
\hline
\end{tabular}

Table A.7: Composition of lead.

Bowman, S.M., 2011. Nucl. Technol. 174, 126-148. Brun, E., et al., 2015. Tripoli- $4^{\circledR}, C E A, E D F$ and AREVA reference Monte

\begin{tabular}{lc}
\hline & ZIRCALOY2 $\left(\right.$ atoms $\left./ 10^{24} / \mathrm{cm}^{3}\right)$ \\
\hline FE54 & $5.5735 \times 10^{-6}$ \\
FE56 & $8.7491 \times 10^{-5}$ \\
FE57 & $2.0205 \times 10^{-6}$ \\
FE58 & $2.6890 \times 10^{-7}$ \\
CR50 & $3.2962 \times 10^{-6}$ \\
CR52 & $6.3563 \times 10^{-5}$ \\
CR53 & $7.2075 \times 10^{-6}$ \\
CR54 & $1.7941 \times 10^{-6}$ \\
NI58 & $2.5163 \times 10^{-5}$ \\
NI60 & $9.6927 \times 10^{-6}$ \\
NI61 & $4.2137 \times 10^{-7}$ \\
NI62 & $1.3432 \times 10^{-6}$ \\
NI64 & $3.4228 \times 10^{-7}$ \\
SN114 & $3.1317 \times 10^{-6}$ \\
SN115 & $1.6381 \times 10^{-6}$ \\
SN116 & $7.0006 \times 10^{-5}$ \\
SN117 & $3.7002 \times 10^{-5}$ \\
SN118 & $1.1674 \times 10^{-4}$ \\
SN119 & $4.1387 \times 10^{-5}$ \\
SN120 & $1.5702 \times 10^{-4}$ \\
SN122 & $2.2308 \times 10^{-5}$ \\
SN124 & $2.7897 \times 10^{-5}$ \\
O16 & $2.9581 \times 10^{-4}$ \\
ZR & $4.2435 \times 10^{-2}$ \\
\hline
\end{tabular}

Table A.8: Composition of Zircaloy-2.

Carlo code, Ann. Nucl. Energy 82, 151-160.

Cao, L., Gerlach, A., Xu, Y., Downar, T., Lee, J. C., 2015. Ann. Nucl. Energy 80, 207-218.

Duderstadt, J.J., Hamilton, L.J., 1976. Nuclear reactor analysis, Wiley, New York.

Dugone, J. (1965). SPERT-III reactor facility: E-CORE revision, IDO-17036.

Grandi, G., 2014. In Proceedings of the PHYSOR2014 conference, Kyoto,

675 Japan

Grandi, G., Moberg, L., 2012. In Proceedings of the PHYSOR2012 conference, Knoxville, Tennessee, USA.

He, X., Ahn, T., Sippel, T., 2001. Corrosion of borated stainless steel in water and humid air, NRC-02-07-006.

680 Heffner, R. E., Wilson, T. R., 1961. SPERT-III reactor facility, IDO-16721.

Houghtaling, J. E., Norberg, J. A., Haire J. C., Addendum to the SPERT-III hazards summary report. Low-enrichment oxide core, IDO-17003.

Kiedrowski, B. C., Brown, F. B., Wilson, P. P. H., 2011b. Nucl. Sci. Eng. 68, 226.

685 Kosaka, I., Kawata, N., Wakabayashi, T., 1988. PNC SN 9410 88-057.

IAEA, 2015. IAEA Technical Reports Series 480, Research Reactor Benchmarking Database: Facility Specification and Experimental Data, Vienna.

Ikeda, H., Takeda, T., 2001. J. Nucl. Sci. Techn. 38, 492-502.

Leppänen, J., et al., 2014. Ann. Nucl. Energy 65, 272.

690 McCardell, R. K., Herborn, D. I., Houghtaling, J. E., 1969. Reactivity accident test results and analyses for the SPERT-III E-CORE - A small oxide-fueled, pressurized-water reactor, IDO-17281.

Nauchi, Y., Kameyama, T., 2005. J. Nucl. Sci. Technol. 42, 503.

Nauchi, Y., Kameyama, T., 2010. J. Nucl. Sci. Technol. 47, 977.

695 Olson, A. P., 2013a. Neutronics calculations for SPERT-III, E-Core, ANL/GTRI/TM-13/10.

Olson, A. P., 2013b. Consolidator's report for the SPERT-III benchmark, ANL/GTRI/TM-13/9.

Olson, A. P., 2013c. SPERT III E-CORE: Facility specifications, Argonne National Laboratory (ANL).

Ott, K. O., Neuhold, R. J., 1985. Nuclear Reactor Dynamics, Am. Nucl. Soci- 
ety.

Potenza, R. M., Haire, J. C., Nyer, W. E., 1966. Quarterly technical report SPERT project, IDO-17206.

705 Sjenitzer, B.L., Hoogenboom, J.E., 2013. Nucl. Sci. Engng. 175, 94-107.

Soon, S. (1995). NEA/NSC/DOC/(95)03/II.

Taxelius, T. G., Potenza, R. M., 1967. Quarterly technical report SPERT project, IDO-17207.

Taxelius, T. G., 1967. Quarterly technical report SPERT project, IDO-17228.

710 Taxelius, T. G., Haire, J. C., Forbes, S. G., 1967. Quarterly technical report SPERT project, IDO-17245.

Truchet, G., Leconte, P., Santamarina, A., Damian, F., Zoia, A., 2015. Ann. Nucl. Energy 81, 17-26.

Tripoli-4 Project Team, 2012. Tripoli-4 User guide, Rapport CEA-R-6316.

715 Wang, R. C., Xu, Y., Hudson, N., Downar, T. J., 2013. Nucl. Techn. 183, 504.

X-5 Monte Carlo Team, 2003. MCNP - A general Monte Carlo N-particle transport code, Version 5, Volume I: Overview and theory. LA-UR-03-1987, Los Alamos National Laboratory.

Yamaji, H., Takemoto, Y., Kirimura, K., et al., 2014. In Proceedings of the PHYSOR2014 conference, Kyoto, Japan.

Zoia, A., Brun, E., Jouanne, C., Malvagi, F., 2012. Ann. Nucl. Energy 54, 218 226.

Zoia, A., Brun, E., Malvagi, F., 2014a. Ann. Nucl. Energy 63, 276.

Zoia, A., Brun, E., Damian, F., Malvagi, F., 2014b. Ann. Nucl. Energy 75, 627. 